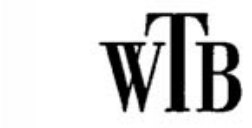

BAND 158

Paul Hoffmann

\title{
Photosynthese
}

mit 77 Abbildungen, 8 Tafeln

und 26 Tabellen 


\section{Reihe BIOLOGIE}

\section{Herausgeber:}

Prof. Dr. H. Bochow, Berlin

Prof. Dr. H. Borriss, Greifswald

Prof. Dr. E. Hofmann, Leipzig

Prof. Dr. J. O. Hüsing, Halle/Saale

Verantwortlicher Herausgeber dieses Bandes.

Prof. Dr. H. Borriss, Greifswald

Verfasser:

Prof. Dr. sc. Paul Hoffmann

Berlin, Humboldt-Universität

Sektion Biologic

1975

(C) Akademie-Verlag, Berlin, 1975

Lizenznummer: $202 \cdot 100 / 528 / 75$

Gesamtherstellung: VEB Druckhaus „Maxim Gorki“", 74 Altenburg

Bestellnummer: 7620303 (7158) - LSV 1314

Printed in GDR

EVP 12,50 
Meinem verehrten Lehrer, Herrn Prof. Dr. habil. H. Borriss, zum 65. Geburtstag gewidmet 
